\title{
La lectura en voz alta y la escenificación: Un camino hacia la comprensión de la narrativa
}

\author{
Reading Aloud and Staging: A Path Towards Literary Narrative Comprehension
}

\section{A leitura em voz alta e a encenação: Um caminho para compreender a narrativa}

Jesús Alberto Leyva-Ortiz Benemérita y Centenaria Escuela Normal del Estado de San Luis Potosí San Luis Potosí, México aleyvao@hotmail.com https://orcid.org/0000-0002-8892-7446

María Azareel Vaca-Morales Benemérita y Centenaria Escuela Normal del Estado de San Luis Potosí San Luis Potosí, México avaca@beceneslp.edu.mx D https://orcid.org/0000-0002-3747-2955

Recibido • Received • Recebido: 19 / 06 / 2018

Corregido • Revised • Revisado: 18 / 10 / 2019

Aceptado • Accepted • Aprovado: 16 / 04 / 2020

\begin{abstract}
Resumen: El presente artículo expone los resultados obtenidos de una propuesta didáctica-literaria que fomentó y representó una herramienta exitosa para la comprensión lectora y con ella aportó experiencias a la enseñanza de la literatura. Consistió en vincular la lectura individual con la lectura en voz alta y la escenificación de la novela La tregua, del autor Mario Benedetti, como estrategia para el acercamiento de la obra. Este proyecto se aplicó en el nivel superior con el personal docente en formación de la Benemérita y Centenaria Escuela Normal del Estado de San Luis Potosí con la participación directa de 32 estudiantes y 8 personas catedráticas en un periodo de diez meses. Los hallazgos consideran una muestra de 81 personas, 40 de ellas como el total de sujetos colaboradores activos y el resto público asistente; y expone datos cualitativos y cuantitativos sobre la importancia y necesidad de la propuesta, hasta la profundización y comprensión de la obra con datos relevantes sobre la eficiencia alcanzada; confiamos en esta contribución que ponemos a su consideración.
\end{abstract}

Palabras claves: Lectura en voz alta, escenificación, comprensión lectora, narrativa literaria, experiencia. 
http://doi.org/10.15359/ree.24-2.25

ROR: https://ror.org/01t466c14 Universidad Nacional, Costa Rica

http://www.una.ac.cr/educare

educare@una.cr

\begin{abstract}
This paper shows the results obtained when applying a literary-didactical proposal, which was a successful tool to encourage reading comprehension and gave rich experiences in the teaching of literature. This project was conducted by 32 pre-service teachers and eight professors from the "Benemérita y Centenaria Escuela Normal del Estado de San Luis Potosí" along ten months. To study Mario Benedetti's novel "La Tregua" (The Truce), the researchers implemented a strategy based on mixing individual reading with reading aloud and role-playing of the book. The results from a sample of 81 participants ( 40 from the staff and the rest from assistants to the events) show qualitative and quantitative data about the need and importance of this work. At the same time, it illustrates how deep and comprehensive the reading was for readers according to the level of reading efficiency reached. Founding on our word and results, we send it to you for your consideration.
\end{abstract}

Keywords: Reading aloud, staging, reading comprehension, literary narrative experience.

Resumo: Este artigo apresenta os resultados obtidos a partir de uma proposta didático-literária que promoveu e representou uma ferramenta de sucesso para a compreensão da leitura e com ela contribuiu com experiências para o ensino da literatura. Consistiu em unir a leitura individual com à leitura em voz alta e encenar o romance $A$ Trégua, de Mario Benedetti, como uma estratégia para compreender a história. Este projeto foi aplicado ao grupo de estudante de ensino da Benemérita y Centenária Escola Normal do Estado de San Luís Potosí de com a participação direta de 32 alunos e 8 professores num período de dez meses. Os resultados consideram uma amostra de 81 pessoas, 40 delas como o total de colaboradores ativos e o restante do público presente; e expõe dados qualitativos e quantitativos sobre a importância e necessidade da proposta, até o aprofundamento e compreensão do trabalho com dados relevantes sobre a eficiência alcançada; confiamos nesta contribuição que colocamos à sua consideração.

Palavras chave: Leitura em voz alta, encenação, compreensão de leitura, narrativa literária, experiência.

\title{
Introducción
}

El desarrollo integral en una persona incluye diversas habilidades que a lo largo de su vida va adquiriendo y todas ellas le resultan fundamentales en la resolución de conflictos, en la manifestación de su creatividad, en la aplicación de situaciones laborales, familiares y un largo etcétera. Una de las herramientas indispensables para la obtención de habilidades es en sí misma es una habilidad también; se trata de la lectura, esta facilita la adquisición de otras habilidades y por tanto, en los centros escolares de cualquier nivel debe fomentarse y consolidarse.

La lectura desde tiempos remotos ha sido pieza clave para la instrucción de los individuos y desde la época moderna, con la invención de la imprenta en Alemania, se convirtió en un bien necesario para educar, en franca expansión en Europa primero y así a lo largo del mundo. Leer es un proceso y como tal inicia desde la descodificación de las grafías hasta la comprensión del texto y la generación de significados; así que es imprescindible instruirse para efectuarla, porque es un fenómeno social; leer nos acerca a las otras personas, nos comunica y desarrolla otras capacidades. Sánchez (2012) plantea:$$
2
$$

Jesús Alberto Leyva-Ortiz y María Azareel Vaca-Morales

Los artículos de la Revista Electrónica Educare del Centro de Investigación y Docencia en Educación de la Universidad Nacional, Costa Rica, se comparten bajo términos de la Licencia Creative Commons: Reconocimiento, No Comercial, Sin Obra Derivada 3.0 Costa Rica. Las autorizaciones adicionales a las aquí delimitadas se pueden obtener en el correo: educare@una.cr 
La lectura es también una herramienta muy valiosa cuyo ejercicio conduce al estudiante a un proceso de interacción con el autor. En este proceso de interacción se espera del estudiante el dominio de un conjunto de habilidades y capacidades mentales que le permitan ingresar al texto, analizar y extraer de él la información de mayor relevancia para su aprendizaje significativo. (p. 22)

Respecto a esta aportación, se respalda el ejercicio de este proceso de interacción en el que, mediante la lectura en voz alta y la escenificación, el personal docente en formación experimentó en acercamiento también al desarrollo de sus habilidades interpretativas e histriónicas frente a una narración literaria como la novela La tregua, de Mario Benedetti, con la cual tuvieron contacto.

Recordar un par de sucesos generales e históricos sobre los usos de la lectura y su enseñanza, particularmente en México, ayuda a tenerlos presentes para realizar algunas puntualizaciones sobre el proceso lector de este documento. Desde la conquista de Tenochtitlán hasta gran parte de la época novohispana la lectura fue empleada para la evangelización; es decir, la intención fue didáctica. La mayor parte de libros leídos eran del orden dogmático; sin embargo, el público lector novohispano, lo mismo podía leer teología, que poesía, jurisprudencia y novelas de caballería.

Para finales del siglo XVII e inicios del XVIII surge, como principal intención ilustrada, la de alfabetizar. El recurso para este ejercicio fueron las cartillas y los silabarios a través de un método de deletreo y la combinación de las sílabas (Cantón, 2009). Y justamente retomando la parte que a métodos se refiere, a lo largo de la historia, de igual manera ha existido diversidad de ellos. Por ejemplo, desde la Edad Moderna se ocupaba la lectura en voz alta como característica para quienes leían. De ahí que surgiera el procedimiento al que se dio el nombre de "Leer escuchando" considerado de tal forma para el aprendizaje (Martínez, 2005).

Así pues, la lectura en voz alta exige no solo hacer una descodificación eficiente; es decir, tener total respeto de los signos ortográficos y de puntuación, sino también de un entusiasmo adicional que exigen las normas de la oralidad como la adecuada dicción, entonación, modulación de la voz y todo ello en conjunto nos vuelve narradores o narradoras si de un texto de ese género leyéramos. María Héguiz, promotora de lectura en voz alta reflexiona, al respecto plantea:

Hemos perdido el hábito de la lectura en voz alta que solía unir y estrechar vínculos entre los miembros de las familias, las comunidades escolares o simples desconocidos. Ahora cada uno está metido en su propia pantalla, su propio mundo. La posibilidad de leer los libros en voz alta, o contarlos, nos acerca a otros mundos que podemos compartir encontrando un lazo común entre las personas. (Valenzuela, 2014, p. 54) 
Cuando leemos en voz alta y nos imponemos hacerlo incluyendo sentimientos y emociones, nos volvemos sujetos actores lectores, o bien, podemos afirmar que se realiza una lectura dramatizada. Este ejercicio del acto lector acaso primero tuvo una tradición doméstica, luego académica como procedimiento de aprendizaje. Por lo anterior, hoy podemos seguir procurando y fomentando el desarrollo de la habilidad lectora haciéndola en voz alta y dramatizándola, creemos y confiamos como personas autoras de este documento en lo que dijo Villoro (2014) en la clausura del Seminario Internacional de Fomento a la Lectura que se llevó a cabo en el marco de la 34 Feria Internacional del Libro Infantil y Juvenil (FILIJ), en el Cenart, en la ciudad de México:

La literatura no se enseña, se contagia, por lo que no hay manera más efectiva que transformarla como una forma de afecto, ya que cuando el abuelo, la madre o el hermano mayor le leen a un niño, convierten la lectura en un vínculo emotivo, no sólo con la trama, sino con la persona que lee. (párr. 13)

La lectura en voz alta y también la escenificación ante un público, es una propuesta que surge como inquietud en la Benemérita y Centenaria Escuela Normal del estado de San Luis Potosí, concretamente en la Licenciatura de Educación Secundaria con Especialidad en Español, a partir de dos materias del tercero y quinto semestre: Seminario de Apreciación Literaria I y de Estrategias Didácticas. Textos Narrativos y Poéticos. Cuando personal catedrático titular de ambas asignaturas, quienes escribimos este artículo, observamos dentro del desarrollo de cada una un bajo ejercicio, en primer lugar, en el hábito por la lectura y además en las dificultades para comprender y profundizar en el análisis de una obra literaria; en este caso particular, de la novela.

Resulta que la lectura sigue siendo actualmente un ejercicio indispensable cuando de ampliar el aprendizaje se trata, y más si de docentes en formación corresponde. A lo anterior, Marchesi (2005) aporta que una lectura que satisface, favorece el progreso en la aplicación de estrategias con un impacto libre y meditabundo e independiente. Confiamos en el ejercicio de la lectura en voz alta, con la idea de compartir lo leído leyéndoles a otras personas. Por el mero placer de escuchar para los sujetos receptores y por el mero placer de contar para los entes emisores, pues ya lo dice Granés en (Vargas Llosa, 2014, p. 13) "Leer es una actividad tan placentera y maravillosa que sencillamente es una tontería privarse de ella".

El presente artículo pretende compartir la experiencia recuperada y reflexionada desde su preparación hasta la puesta en escena del proyecto de lectura en voz alta y escenificación, donde la novela La tregua del autor Mario Benedetti, fungió como la inspiradora para su efecto. La población elegida para su desarrollo fue el personal docente en formación de la Licenciatura en Educación Secundaria con Especialidad en Español de los semestres primero, tercero, quinto y séptimo de la Benemérita y Centenaria Escuela Normal del Estado de San Luis Potosí. El trabajo 
de dicho proyecto se originó desde la lectura, afición y luego con la adaptación de la novela en mención para ser llevada a la escena. Para ello se consideraron una serie de factores, como la elección de los capítulos más significativos y así conservar la esencia de la historia relatada.

Se contempla la opción de los espacios pertinentes para la recreación de los momentos que se pretendían reproducir en la escenificación y así mismo de los personajes que debían reaparecer para su dramatización. ¿Por qué leer novelas?, el propio Mario Granés, en el prólogo que escribe en la publicación de Lección de lectura de Vargas Llosa, explica el porqué de la importancia de leer novela, hablando justamente del escritor peruano como ejemplo:

Las novelas eran poderosos artefactos subversivos: eso lo descubrió Vargas Llosa a medida que maduraba y se ejercitaba en la escritura. La literatura producía en el lector una enorme insatisfacción. Leyendo libros no sólo se pulía y ensanchaba la sensibilidad, sino que se afilaba la visión crítica y el espíritu de contradicción. Las novelas eran mundos paralelos que superaban con creces al real, y sumergirse en ellos no dejaba indiferente. (Granés, 2014, p. 17)

Por lo tanto, a lo largo del desarrollo de las siguientes líneas, se pretende dar respuesta a estas interrogantes: ¿Leer sigue siendo esencial para un individuo y aún más para docentes? ¿Por qué la importancia de abordar la comprensión de una lectura narrativa con la adaptación de una novela? ¿Por qué vincular la lectura en voz alta con la escenificación? ¿La lectura en voz alta y la escenificación colaboran en el desarrollo y consolidación de las habilidades para la comprensión necesaria en docentes en formación? ¿La lectura en voz alta y la escenificación favorecen la comprensión de una novela como La tregua de Mario Benedetti?

El propósito de esta investigación es contribuir con una propuesta didáctica-literaria que pretende no solo fomentar la lectura, sino generar herramientas para la comprensión lectora y con ello, sumar aportaciones en la enseñanza de la literatura. Demostramos cómo la vinculación entre la lectura individual con la lectura en voz alta y la escenificación de la novela La tregua del escritor Mario Benedetti, ayuda a la comprensión de la obra narrativa.

El objeto de estudio se tomó de una muestra de 81 docentes en formación, con resultados obtenidos en las materias Seminario de Apreciación Literaria y Estrategias Didácticas. Textos Narrativos y Poéticos que actualmente cursan en los semestres III y $\mathrm{V}$ respectivamente dentro de la Licenciatura en Educación Secundaria con Especialidad en Español.

\section{Metodología}

Se basa en un enfoque mixto porque recupera elementos cuantitativos y cualitativos. En lo que respecta a lo cuantitativo, se aplicaron dos instrumentos: el primero permitió recabar el impacto de las impresiones en el público espectador y participantes dentro del desarrollo de 
la lectura en voz alta y escenificación de la novela adaptada de La tregua; el segundo, conocer qué tanto comprendieron el texto. Las dos actividades son igualmente importantes, porque se realizó la lectura en voz alta y la escenificación para un público expectante quien debió comprender la historia de la novela a través de la adaptación escénica que presenció y quienes la realizaron se involucraron de tal modo que pudieron profundizar en la historia contada.

El proceso efectuado para la realización de este proyecto, en primer lugar tuvo como objetivo involucrar a quienes estarían dentro del reparto para la lectura en vozalta y escenificación de la trama. Es importante señalar que se convocaron profesores y profesoras de la licenciatura y estudiantes de los cuatro grados; la convocatoria fue abierta, hubo audiciones, elección de personas lectoras y actoras de acuerdo con el perfil necesario para la representación. El total de participantes que se eligió fue de 40, de quienes ocho docentes y el resto estudiantes; se trabajó durante diez meses, desde la adaptación de la obra que inició en el mes de mayo de 2016 hasta la lectura y puesta en escena a finales del mes de febrero de 2017. Aquellas personas que no leyeron ni actuaron, pero que estuvieron tras escenario, encargadas de vestuario, iluminación, sonido, escenografía, guiones y otras tareas, también se involucraron en el proceso lector, todas abordaron la lectura completa de la novela, para posteriormente identificar personajes, situaciones, lugares y la esencia de cada parte que la integra. En palabras de Garrido (2014b), este proceso es imprescindible:

Lo más importante para leer en voz alta es comprender el texto antes de emprender la lectura. A partir de eso se tomarán todas las decisiones sobre tono, estilo, pausas, ritmo. Lo más importante es que las inflexiones de la voz, los silencios, los gestos, la actitud y los comentarios del lector transmitan a sus oyentes lo que haya que entender: ¿hay que reírse?, ¿o asustarse?, ¿hay datos que vale la pena recordar?, ¿cómo son los personajes?, ¿se relaciona esa historia con otras que ya se hayan visto antes?, ¿y con la vida fuera de los libros, con el mundo? (p. 88)

Posteriormente ocurrió la sensibilización para quienes intervendrían en las lecturas y actuaciones. Se trabajó con un método para la sensibilización y representación escenificada, tomando como eje la estrategia vivencial, para la cual se ocupa motivar al actor o actora a realizar una conexión con su propia vida, ubicando el yo sujeto actor desde su existencia llevada hacia afuera de sí en las cualidades que tiene que potenciar en su papel asignado para la escena (Rocamora, 2015). De tal manera que, para poder marcar la dramatización y los trazos escénicos, fue indispensable que cada parte colaboradora tuviera un amplio y exhaustivo conocimiento de la obra completa y en específico de su personaje por interpretar. Este ejercicio de interiorización Felipe Garrido (2014b) lo explica así: 
Los cuentos, las novelas y el teatro plantean conflictos y los conflictos nos interesan: nos hacen experimentar emociones, como dice Pacheco, al mismo tiempo ajenas y propias, pues "por un instante yo soy el otro". Por otra parte, sabemos que en lo que leemos o escuchamos iremos encontrando claves para nuestra propia vida. Tomamos consciencia de lo que le sucede a otros y, al mismo tiempo, exploramos nuestro interior. (p. 90)

Los ensayos comenzaron en el mes de noviembre con 16 sesiones con mínimo tres horas cada una de trabajo, la meta fue presentarlo en el mes de febrero y así ocurrió el último día de ese mes en el marco de los festejos del 168 aniversario de la Benemérita y Centenaria Escuela Normal del Estado de San Luis Potosí en su Auditorio Prof. Pedro Vallejo con audiencia llena de 500 butacas. Los instrumentos aplicados a los sujetos participantes de este proyecto se realizaron días posteriores a esta presentación en la plataforma electrónica de la institución.

\section{Resultados}

A continuación, presentamos los resultados de los instrumentos aplicados en la lectura dramatizada de la novela. Es importante considerar las voces de quienes se involucraron en este trabajo, porque gracias a su actividad dentro del ejercicio, consolidaron lo leído, pusieron en marcha habilidades que se adicionaron al proceso lector y que tienen que ver con la interpretación; no es el mismo proceso solo leer e imaginar el texto a leer y representar. Porque en el segundo caso, el esfuerzo se materializa en actuación, impostación de voz, pero sobre todo en la apropiación de un modo de ser o de ver el mundo que tienen los personajes en sí mismos.

La pregunta uno fue: ¿Consideras importante realizar una adaptación de una novela para la lectura en voz alta y escenificada? Con esta pregunta es evidente que medimos la importancia de la actividad y más del $80 \%$ estuvo de acuerdo en lo valioso de hacerlo. Pero concretamente observamos la compatibilidad entre la adaptación de una novela y la lectura dramatizada en quienes lo experimentaron, y el resultado es una buena relación entre ambas actividades. Los sujetos encuestados determinan que una adaptación novelística le va bien a la lectura escenificada y viceversa.

La pregunta dos: ¿Te gustó haber participado en una puesta en escena como la adaptación de la novela La tregua de Mario Benedetti? Aquí se pudo valorar el gusto de participar por implicarse directamente en la puesta en escena de la adaptación de una novela, ello representa considerar que la parte emocional y la gratificación de contribuir para el desarrollo de la actividad resulta básico. El desempeño de la dramatización y la lectura en la narración de una novela involucran factores tales como la disposición, de tal modo que, si a un participante le es grato realizarlo, suma a un avance más pleno al momento de representarlo; así podemos apreciar que un $78 \%$ de quienes intervinieron para esta puesta manifiestan en afirmativo este aspecto. 
La pregunta tres: ¿Pudiste conocer a fondo la obra siendo partícipe de la lectura en voz alta y la escenificación? Es importante aclarar que para este cuestionamiento empleamos cinco opciones de respuestas que incluían términos como la nulidad, la parcialidad y la totalidad para dar libertad a las personas participantes de expresar el grado de hondura lograda con su intervención. Las diferencias en lo respondido podrían darnos no únicamente la asertividad, sino también las áreas de oportunidad y aunque esta última, como se verá en la imagen, resultó con mínimos porcentajes, motiva y permite confirmar que los sujetos participantes, efectivamente, vieron en el proyecto un espacio para mejorar su proceso lector.

Figura 1: Conocimiento profundo de la novela al participar

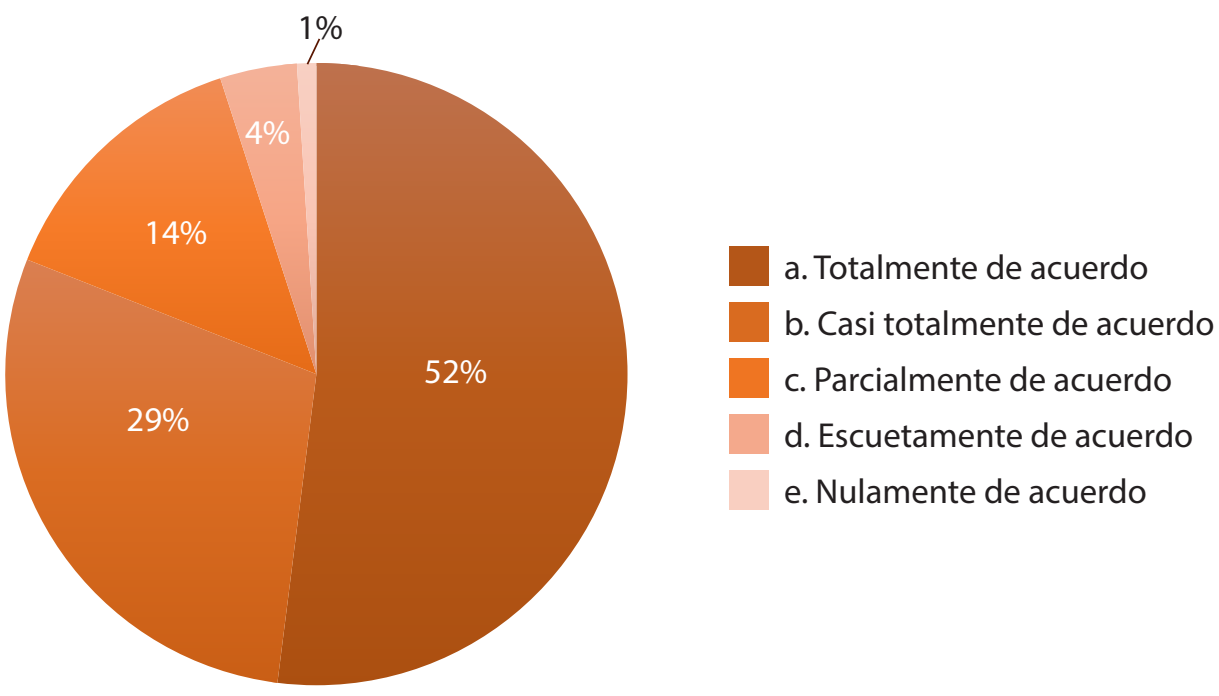

Nota: Elaboración propia.

La Figura 1 señala que $52 \%$ de las personas participantes sí logró profundizar totalmente en la historia gracias a la actividad y un $29 \%$ casi totalmente, datos que sumados dan $81 \%$ de efectividad en este rubro, dado que cuando se le cuestiona al personal docente en formación sobre si conocieron "a fondo" la obra, hacemos referencia a la profundidad con la que lograron comprender la historia en la que participaron.

Representar una escena involucra y enfrenta a las personas con diversos elementos del contexto y de la estructura interna tales como tiempo, espacio, emociones, sentimientos, situaciones, etcétera; por lo cual, al momento de tener que escenificar, el personal docente en formación estuvo en contacto con dichos elementos y es inevitable la interacción y la confrontación entre sus propias personalidades y las personalidades de los personajes de la 
historia. Se pueden dar, entre otras situaciones propias de la interacción, una relación de amor y odio entre quien interpreta y los personajes protagonistas; así, esta relación e involucramiento con el texto es un proceso natural de comprensión: "donde realizan sucesivas lecturas de la obra, la división en unidades (temas), que permitirán aclarar los contenidos y las premisas de la misma, así como también las características de los personajes, sus objetivos, los obstáculos y resistencias a los que se ven enfrentados durante la obra, la época en la que ésta ocurre, la música, el sonido, etc." (Astete et al., 2013, pp. 36-37).

La pregunta cuatro: ¿Te parece interesante conocer la historia de una novela retomada a través de la lectura en voz alta y la escenificación? Cuando se está frente a grupo y, como responsables de asignaturas que involucran la lectura permanente, tenemos la obligación de recurrir a diferentes alternativas para propiciar el acercamiento del estudiantado, tanto al conocimiento como a la apropiación de la historia escrita. La lectura en voz alta y la escenificación son recursos que bien pueden ayudar a desarrollar habilidades de comprensión y análisis de textos narrativos como en este caso la novela, porque todos los sujetos lectores se implican en ambas actividades, Solé (2009) lo explica así:

La lectura es más comprometida cuando se vincula a proyectos globalizados, a tareas académicas relacionadas con la realidad y a las que los estudiantes pueden dar sentido. El carácter colaborativo (entre docente y alumnos, y entre éstos) que suelen tener estos proyectos añade un plus de motivación, que puede ser explicado por el carácter a la vez cognitivo y afectivo que poseen las interacciones articuladas alrededor de un proyecto del que todos se sienten responsables, y en que el éxito de cada uno depende del éxito de los demás. (p. 58)

Tal como ha ocurrido en este caso de la adaptación de la novela La Tregua de Benedetti (2003), las personas participantes se responsabilizaron de la puesta en escena y prepararla se convirtió en un proyecto colaborativo que pudo interesar y motivar al personal docente en formación en esta trama. El interés por lo leído ayuda a la construcción de significados.

Se evidencia en el porcentaje mayoritario de las respuestas, el 93\% se muestra totalmente de acuerdo, dejando un mínimo porcentaje para los incisos casi y parcialmente de acuerdo. Se confirma así que la lectura en voz alta y la escenificación resulta un recurso didáctico de interés, pues lleva a quienes la practican a conocer y comprender una novela; pero a lo anterior se adiciona el hecho de tener la oportunidad, al representar a un personaje, de ocupar una vida diferente a la propia, de poder mirarse reflejado desde ser "otro"ser y así mismo a reflexionar sobre una similitud en el actuar (Delgado, 2011).

La pregunta cinco: ¿A partir de tu participación en la lectura escenificada pudiste comprender la historia narrada? 
Figura 2: De la participación a la comprensión de la historia. Elaboración propia

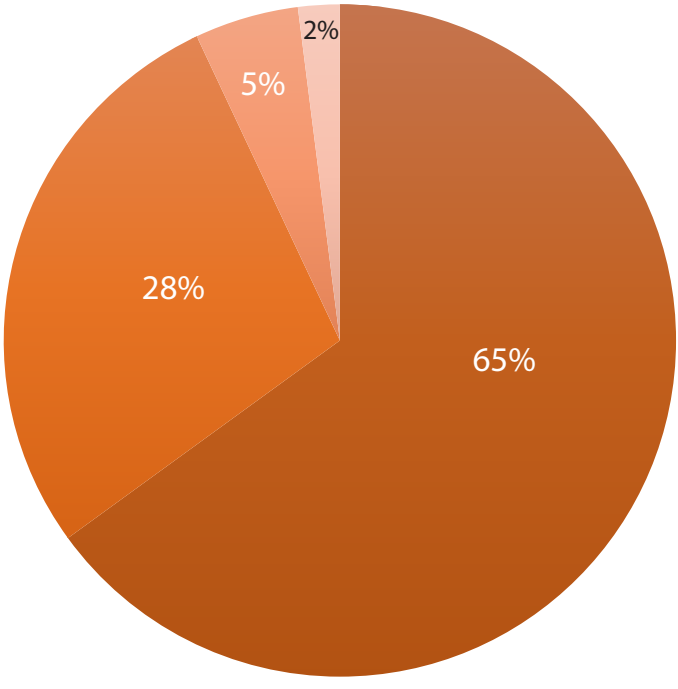

Nota: Elaboración propia. a. Totalmente de acuerdo

b. Casi totalmente de acuerdo

c. Parcialmente de acuerdo

d. Escuetamente de acuerdo

En todas las preguntas previas, se alude al interés y a la importancia de la actividad didáctica de la lectura escenificada de la novela de M. Benedetti y, una de ellas en particular, nos ilustra si lograron profundizar; todas ellas dieron porcentajes aceptables que bien pueden conciliarse con esta pregunta cinco. Los sujetos encuestados contestan positivamente, entre el $65 \%$ de totalmente de acuerdo y el $28 \%$ de casi totalmente de acuerdo suman el $93 \%$; es decir que solo un $7 \%$ considera no haber comprendido la obra gracias a su participación de esta actividad.

Se pudiera pensar que una simple pregunta no demuestra si lograron esa comprensión, aunque respondieron afirmativamente no hay datos que lo sustenten. Así que en las preguntas siguientes hemos preparado cuestionamientos concretos que pueden demostrar que, efectivamente, comprendieron, porque se recaba información concisa sobre el contenido y la trama, de tal forma que esos resultados puedan contrastarse con esta Figura 2.

Pregunta seis: El título de la novela La Tregua se relaciona con la historia narrada, en razón de que al protagonista la vida le ofrece: 
Figura 3: Del título a una historia de vida

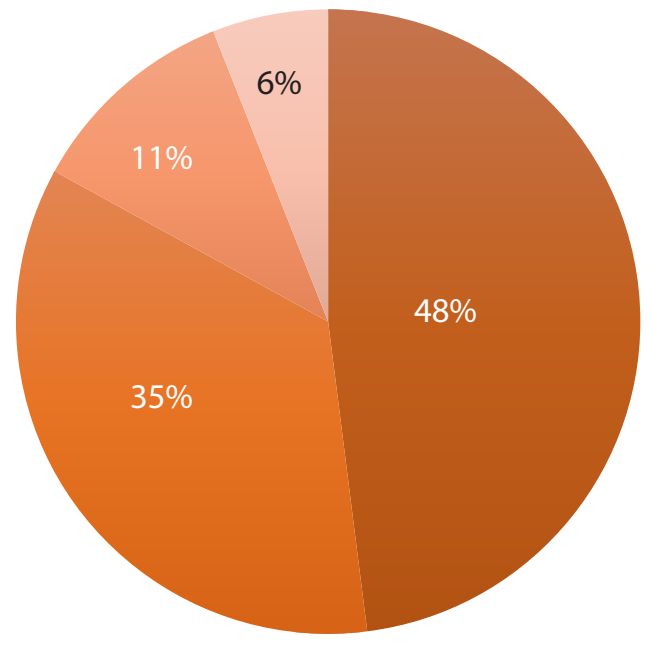

a. Cese temporal de una vida gris con un nuevo amor

b. Detenerse a pensar en su vida

c. Un tiempo de descanso entre problemas

d. La opción de resolver los problemas con sus hijos

Nota: Elaboración propia.

En la interpretación de una forma explícita los sujetos participantes revelan ese verdadero sentido de haber participado de un proyecto de esta naturaleza, pues demuestran que han comprendido la historia en sí. Como puede observarse en los datos graficados en la Figura 3, casi la mitad, es decir un $48 \%$ responde acertadamente que el protagonista de la novela hace un alto en su vida gris y se da otra oportunidad para el amor.

La respuesta que ocupó el segundo lugar en la elección con un 35\% es aquella relacionada a que el protagonista decide detenerse a pensar en su vida; tal opción elegida de igual manera se acerca a la esencia de la trama, para lo cual retomamos el texto original de la novela de Benedetti (2003) donde relata, en relación al término "tregua", lo siguiente:

Es evidente que Dios me concedió un destino oscuro. Ni siquiera cruel. Simplemente oscuro. Es evidente que me concedió una tregua. Al principio, me resistí a creer que eso pudiera ser la felicidad. Me resistí con todas mis fuerzas, después me di por vencido y lo creí. Pero no era la felicidad, era sólo una tregua. Ahora estoy otra vez metido en mi destino. Y es más oscuro que antes, mucho más. (p. 200)

De ahí lo enriquecedor de las líneas de la cita anterior, pues evidencian la parte medular de la historia en referencia al concepto de "tregua", de la cual Umaña Chaverri (1989) aporta una visión que compartimos con él: 
La tregua, como núcleo semántico, se instaura en tres niveles que se incluyen, sucesivamente, uno al otro en el siguiente orden: a) como el tiempo (y los apuntes que lo recogen) en que se establece la relación Santomé-Avellaneda; b) como el texto todo (desde el primero hasta el último apunte) y c) como novela. El relato se da como un espacio globalizador (la novela) que integra el espacio del diario y éste último da cabida a un espacio, aún más reducido, de donde se desprende el eje semántico de todo el texto. (p. 142)

Podemos afirmar, entonces, si sumamos los porcentajes de ambas respuestas que el $83 \%$ de los participantes en el proyecto de la lectura en voz alta y la escenificación de la novela de Benedetti, manifiestan con asertividad esa congruencia entre la historia del relato representado y el título que el autor asigna para la misma.

Con base en los datos del párrafo anterior podemos señalar que un 17\%, al reflexionar sobre el vínculo entre el título y el contenido de la obra, no fueron capaces de atinar a la esencia de la situación del personaje principal y llama la atención que eligieron vínculos menos pertinentes que el resto, aun cuando la adaptación, lectura y escenificación hacen énfasis implícito en el concepto de la palabra "tregua"; eso nos hace pensar en la necesidad de implementar en próximos proyectos una estrategia específica en el proceso para discutir esas relaciones entre lo que ocurre en la historia y la palabra o frase que le da título.

Pregunta siete: ¿Qué cualidades atribuirías al personaje de Laura Avellaneda?:

Figura 4: Cualidades para Laura Avellaneda en La Tregua

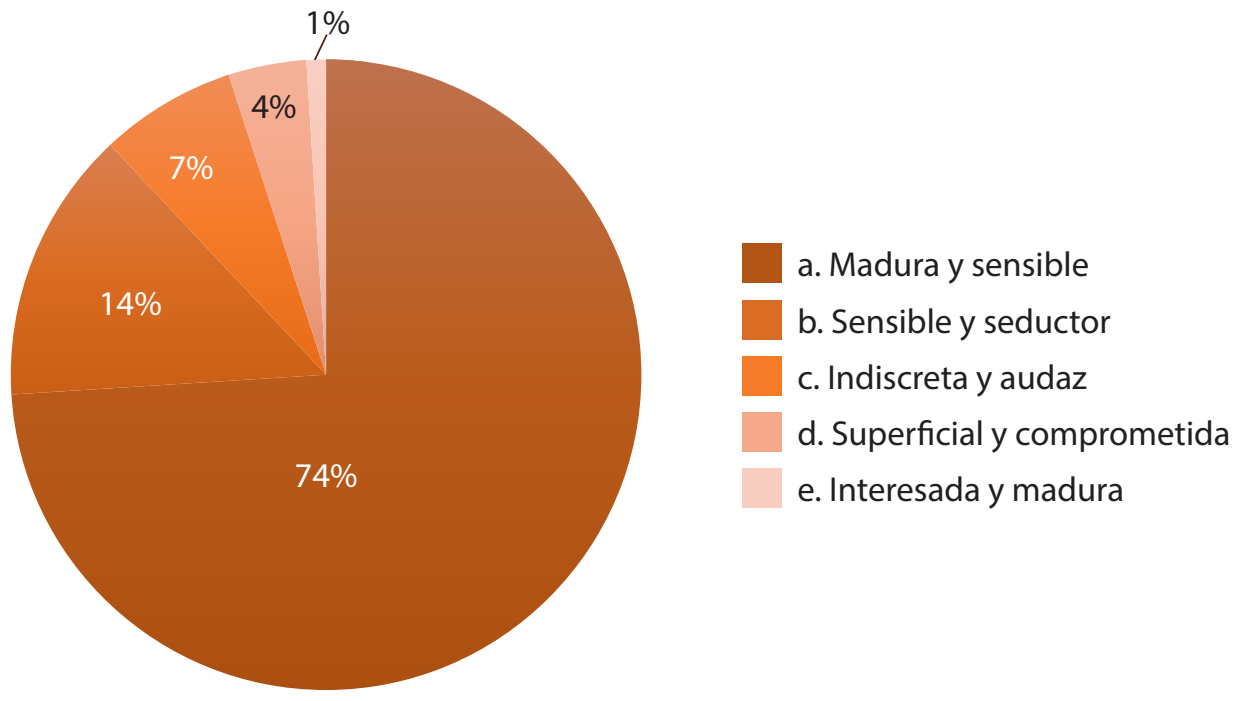

Nota: Elaboración propia. 
Identificar las cualidades de un personaje resulta más complejo de lo que parece, porque requiere una comprensión de la historia, profundizar en su estructura y todas las partes que la integran. Los datos de la Figura 4 señalan con precisión la opción más pertinente a las atribuciones de la personalidad de la coprotagonista Laura Avellaneda. El 74\% califica a este personaje femenino como "madura y sensible", lo cual demuestra con un dato concreto, que el personal docente en formación realmente tuvo acercamiento y comprensión de la obra a través de la lectura en voz alta y la escenificación.

Para poder mostrar asertividad en responder a esta pregunta, el personal docente en formación tuvo que haberse adentrado en la personalidad de Laura Avellaneda y así contestar apropiadamente a este planteamiento; podemos reflexionar que cada persona como lectora evoca o imagina a los personajes en su mente gracias a lo narrado, pero cuando existe la opción de que se representen a través de una actriz como en este caso, es más evidente observar en ella esos rasgos que solo entre líneas del texto impreso se infieren. Confirmamos que la representación es una estrategia sólida, porque ofrece la posibilidad de convertir ese personaje de tinta en uno de carne y hueso.

Por lo anterior, afirmamos que los datos obtenidos son positivos y alentadores, porque pueden ayudar a corroborar lo que la mayoría respondió, como puede apreciarse en la siguiente Figura 5 que demuestra que tres cuartas partes de la muestra son capaces de detectar en el protagonista la raíz del conflicto.

Pregunta ocho: La problemática más significativa del protagonista Martín Santomé es deíndole:

Figura 5: Sobre "Martín Santomé" y sus problemas

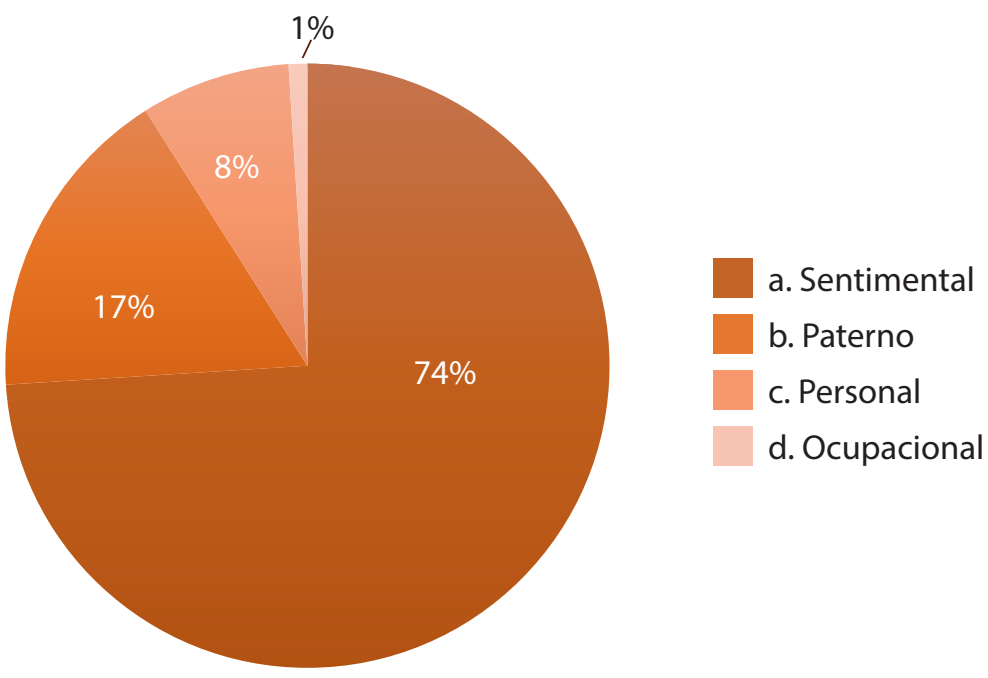

Nota: Elaboración propia. 
http://doi.org/10.15359/ree.24-2.25

ROR: https://ror.org/01t466c14 Universidad Nacional, Costa Rica

http://www.una.ac.cr/educare

educare@una.cr

Esta pregunta bien puede representar cierta complejidad, porque pide hacer una interpretación; así que la respuesta más pertinente será la más apegada a la estructura de la novela. Solo quien conoció y se involucró en la historia relatada mediante la lectura en voz alta y la escenificación, pudiera dar una respuesta más apegada a la trama.

Lo que muestra esta Figura 5 es que la elección de la mayoría (un 74\%), es aquella que atribuye lo sentimental como la problemática más significativa a la que se enfrenta el protagonista dentro de la narración, elección que resulta cierta y más adecuada de acuerdo con el contenido de la obra. Santomé es un personaje que antes de conocer a la coprotagonista Avellaneda mostraba una personalidad gris y cuando ella aparece en su vida, cambia gradualmente su forma de ser; sin embargo, la historia dará un vuelco con la muerte de la joven y él tiene que aprender a vivir con ese destino.

La segunda respuesta con mayor porcentaje es aquella con un 15\%, cuya opción atribuye a lo paterno el problema central de "Martín Santomé" el protagonista; dato apegado igualmente a la historia en cuestión, pero menos pertinente que la opción elegida por la mayoría. Si bien es cierto que Santomé se encarga de sus hijos y de los problemas de cada uno de ellos, este hecho no es el principal en la historia, eso ocupa un lugar secundario, frente al hecho de la relación amorosa entre el protagonista y la joven.

Al contrastar este dato de asertividad del $74 \%$ frente a lo que los sujetos encuestados señalaron en el planteamiento cinco que aludía a la comprensión de la obra, vuelve a corroborar que contestaron con la verdad al afirmar que comprendieron la novela gracias a la lectura en voz alta y la escenificación.

Pregunta nueve: Considerando la intervención de cada uno de los personajes de la novela, si tuvieras que elegir uno para ocupar su lugar en la historia, ¿cuál serías? Esta pregunta buscó encontrar el vínculo entre el lector o lectora y la historia, justo en esa relación que se establece de identificación con algún personaje, hecho que trasciende los límites de la persona y esta, siente afinidad por el protagonista o antagonista o cualquier otro personaje incluso secundario. Existe un dato relevante que ayuda también a comprender la tendencia en la respuesta a este cuestionamiento y es que la mayoría de participantes en el proyecto son mujeres, eso contribuyó a que la mayoría; es decir el 64\% eligiera haberse identificado o gustar ser Laura Avellaneda, a pesar de que esta muere al final de la historia. Se observó que un $10 \%$ eligió ser el protagonista, pero se explica esta tendencia por la abrumadora mayoría de damas participando en el proyecto.

Lo trascendente es haber encontrado que los sujeos participantes eligieron ser hipotéticamente un personaje y, eso demuestra el vínculo que se estableció entre lector o lectora y lectura; hubo compenetración con la historia y se estrecharon los lazos entre el texto y aquellos que lo entendieron, en forma tal que estos últimos se permitieron adentrarse e identificarse directamente con un personaje y sentir empatía por él. 
Es importante considerar que relacionar lo leído con la vida personal de quien lee parece una actividad sencilla, no siempre resulta así, porque para lograrlo se necesita establecer una conexión análoga entre el contenido de la historia y la vida personal. Para conseguirlo creemos firmemente en que leer en voz alta, emulando a un personaje o narrador, o bien representarlo en carne propia, crea un puente de comunicación más sólido entre lo leído y la vida personal, hay una comprensión de lo vivido por el personaje y eso hace comprender lo que siente, piensa o hace y las razones del porqué su sentir, pensar y obrar.

Pregunta diez: ¿Qué momento representa el nudo más significativo de la historia?

Figura 6: Hablando del nudo en La Tregua

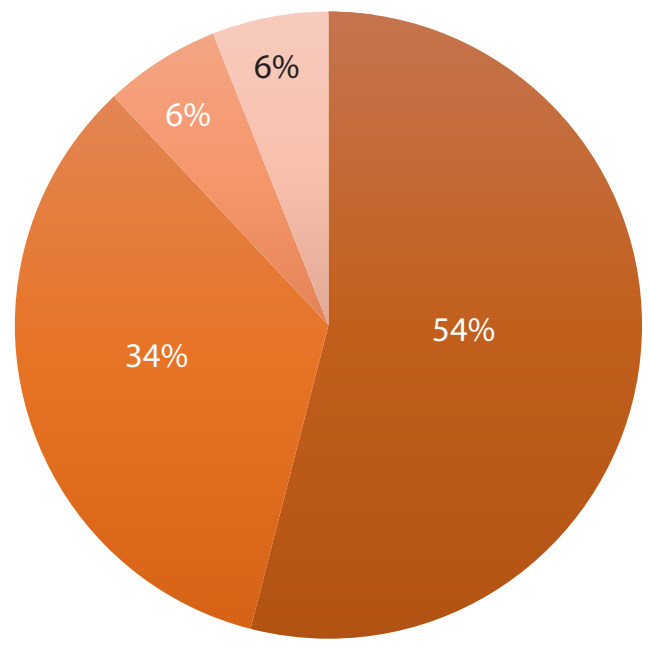

a. Cuando Santomé pierde comunicación con Avellaneda

b. Cuando Avellaneda y Santomé tienen la primera cita

c. Cuando Avellaneda conoce a Blanca

d. Cuando Avellaneda conoce a Santomé

Nota: Elaboración propia.

Este cuestionamiento que refleja la Figura 6 hace referencia al problema más significativo de la historia y más de la mitad elige la opción "cuando Santomé pierde comunicación con Avellaneda" que es la respuesta más pertinente; es decir el $54 \%$ elige lo más asertivo. Este porcentaje viene a confirmar que más de la mitad conoció la historia, en forma tal, que es capaz de determinar el problema principal de la obra.

Resulta evidente en un primer momento, según los resultados de este instrumento, la trascendencia e importancia de la actividad de la lectura en voz alta y la escenificación para los participantes que se desempeñaron como lectores y lectoras, y actores y actrices; personal tramoyista, escenógrafo, de iluminación, de audio, de vestuario, de caracterización, etc., pues consideran que realizar una adaptación de la novela original "La Tregua" fue importante, porque sintetiza su esencia, lo que a su vez generó, de manera adicional, un gusto al haber sido colaboradoras y colaboradores activos. 
http://doi.org/10.15359/ree.24-2.25

ROR: https://ror.org/01t466c14 Universidad Nacional, Costa Rica

http://www.una.ac.cr/educare

educare@una.cr

Este esfuerzo les permitió la oportunidad de conocer a fondo la trama, pues tuvieron que sumergirse en cada momento del relato para poder desplegar su intervención o representación en la puesta en escena y la lectura. La experiencia la asumieron como una estrategia interesante para propiciar la comprensión de la novela, el tema, problemáticas y características y los momentos más significativos de la estructura de la narración, así como identificarse de tal modo, que tuvieron discernimiento de intenciones, personalidades y finalidades de los personajes con los que sintieron empatía.

\section{Conclusiones}

Leer sigue siendo esencial para el aprendizaje de los individuos y para docentes en formación, puesto que tienen el compromiso de trabajar con ella como un medio fundamental de enseñanza y aprendizaje. Se añade a lo anterior, la trascendencia que tiene para aquellos futuros grupos docentes en educación secundaria con especialidad en español, por tratarse de la lengua materna; entonces, la lectura de todo tipo de textos es básica, pero esencialmente la literaria que permite, por sus características de ser la parte artística de la lengua, entre otras opciones acercarse a sus contenidos con los recursos de la escenificación.

Por lo anterior, la lectura en voz alta y la escenificación son un recurso didáctico importante para abordar la comprensión de una obra narrativa, más aún cuando se hace el esfuerzo de realizar la adaptación de una novela para su representación, lo cual implica la capacidad de sintetizar el texto eligiendo partes esenciales que permitan contar la historia desde una perspectiva propia de quienes la adaptan.

Ahora bien, la lectura en voz alta es un ejercicio que atiende al menos tres de las cuatro habilidades fundamentales del español: leer, escribir, hablar y escuchar, de tal modo que si se realiza una lectura en voz alta atractiva, porque su entonación, el manejo del volumen, las pausas y los silencios, se engola, matiza y dramatiza, los beneficios son mejores en aras de la comprensión, pues el esfuerzo lector bien puede ayudar a revelar emociones y sentimientos implícitos en el texto como alegría, dolor, temor, etc., así las admiraciones, preguntas, afirmaciones y frases imperativas, entre otras, se vuelven explícitas. Todavía al trabajo lector se agrega la actividad de la escenificación, se logra, así, una conjunción de ambas actividades al representar lo leído, de este modo, tanto participantes en lectura y actuación como sujetos espectadores alcanzarán a visualizar lo narrado y, con ello, a través de los personajes, representar una realidad, una historia contada en carne viva, hecho didáctico que es todavía más significativo para todos y todas, pues involucrarse en proyectos de esta naturaleza garantiza no solo conocer sino profundizar en el texto.

Por lo tanto, vincular la lectura en voz alta con la escenificación es un recurso con varios beneficios, así que practicarlo y realizarlo con docentes en formación contribuye en el desarrollo y consolidación de las habilidades para la comprensión lectora de futuros docentes, y estos a su vez, lograrán desarrollarlas en el proceso de enseñanza y aprendizaje en las aulas de educación básica.

16 Jesús Alberto Leyva-Ortiz y María Azareel Vaca-Morales

Los artículos de la Revista Electrónica Educare del Centro de Investigación y Docencia en Educación de la Universidad Nacional, Costa Rica, se comparten bajo términos de la Licencia Creative Commons: Reconocimiento, № Comercial, Sin 0bra Derivada 3.0 Costa Rica. Las autorizaciones adicionales a las aquí delimitadas se pueden obtener en el correo: educare@una.cr 
Elegir la narrativa como género literario a leer, adaptar y comprender resulta provechoso en todos sentidos, máxime cuando pensamos en una novela, no solo por leer una obra artística en sí mismo, sino porque es flexible didácticamente hablando: se nos cuenta una historia con estructura básica de planteamiento, nudo y desenlace, tiene personajes, se compone de acciones y existe un contexto o situaciones. Por lo tanto, las novelas son viables de comprender a través de la lectura en voz alta y la escenificación, aquí recordamos los pasos realizados al respecto en este artículo:

a) Elegir una novela

b) Involucrar al grupo en su lectura

c) Adaptar el texto para ser llevado a la escena o representación

d) Seleccionar papeles y funciones mediante un casting

e) Hacer un grupo de lectores y lectoras en voz alta que cuenten la historia

f) Generar un grupo de actrices y actores para que representen partes esenciales de la historia

g) Comprender y profundizar a través de la práctica de la lectura en voz alta y la representación

h) Presentar la obra en público.

No hay esfuerzo menor en la formación de docentes si de lectura se trata, hay que unir esfuerzos porque se lea, es claro que leer es comprender; ahora bien, si eso que se lee es literatura y podemos implementar estrategias didácticas, ya no de acercamiento sino de apropiación de los textos sumamos futuros grupos docentes que desarrollarán habilidades para el proceso de enseñanza y aprendizaje con aprecio y sensibilidad literarias tan indispensables hoy en día en un mundo tan complicado como el que vivimos.

En este artículo la lectura en voz alta y la escenificación favorecieron a la comprensión de la novela La Tregua de Mario Benedetti. Esta obra latinoamericana y contemporánea en sí misma es representativa de este género en el continente americano; la crítica literaria la sitúa como trascendente, no solo porque dio a conocer al escritor uruguayo en el mundo de las letras, sino porque su contenido es tan humano, cuenta una historia de amor entre un hombre de 49 años y una mujer de 24 , de relaciones personales y familiares entre un padre viudo a punto de la jubilación y sus hijos adultos jóvenes. Lo que sucede en el texto sucede también en el interior del personaje principal, es un drama existencial que hace, desde las primeras líneas, una empatía natural por lo ahí narrado. 
Con un total de 500 personas como público espectador en general, más 40 personas en escenario, y considerando 81 individuos de los cuales se incluyen a todos los sujetos involucrados en el proyecto, concluimos que el $80 \%$ afirmó la importancia de la adaptación de una novela para la lectura en voz alta y la escenificación, el 78\% señaló el gusto por participar en el proyecto. El $81 \%$ confirmó lograr conocimiento profundo de la obra con el proyecto y el $93 \%$ el haber despertado su interés con esta modalidad de trabajo.

Con respecto al acercamiento y comprensión de la novela La tregua, el 83\% asertó al relacionar el título con el contenido. El 74\% calificó con la mayor pertinencia la problemática del protagonista Martín Santomé e identificó cualidades sobre la personalidad de la coprotagonista Laura Avellaneda. Finalmente, el 54\% de la muestra fue capaz de encontrar el problema principal o más significativo en esta novela.

Por lo anterior, al considerar los datos arriba descritos en porcentajes se obtiene un promedio de $77.60 \%$ de eficiencia en la valoración del proyecto. Con esas cifras confiamos en la esperanza y certeza de que emplear propuestas didácticas-literarias como esta, bien vale la pena en función de la profundización y comprensión de textos literarios, siempre tan necesarios en el acervo de cualquier lector o lectora y fundamentales en el proceso de enseñanza-aprendizaje al que nos dedicamos.

\section{Referencias}

Astete, P., Cruz, M. y Montero, M. (2013). El teatro al rescate de la comprensión lectora (Tesis de licenciatura). Universidad Académica de Humanismo Cristiano, Santiago de Chile. http:// bibliotecadigital.academia.cl/handle/123456789/1840

Benedetti, M. (2003). La tregua. Uruguay: Alfaguara.

Cantón, A. (2009). Historia de la lectura en México. Hacia la formación de lectores autónomos. (Segunda parte). Correo del Maestro, 163, 31-49. https://www.correodelmaestro.com/ anteriores/2009/diciembre/2incert163.htm

Delgado, M. E. (2011). La dramatización, recurso didáctico en la educación infantil. Pedagogía Magna, 11, 382-392. https://dialnet.unirioja.es/descarga/articulo/3629264.pdf

Garrido, F. (2014a). El buen lector se hace, no nace. Reflexiones sobre la lectura y la escritura. Paidós.

Garrido, F. (2014b). Para leerte mejor. Paidós.

Granés, M. (2014). Prólogo. En M. Vargas Llosa (Autor), Lección de lectura (Colección El elogio de la educación. Consejo de mentes brillantes, pp. 1-18). Editorial del Magisterio “Benio Juaréz". 
Marchesi, Á. (2005). La lectura como estrategia para el cambio educativo. Revista de Educación, Extraordinario, 15-35. https://www.yumpu.com/es/document/read/45066311/la-lecturacomo-estrategia-para-el-cambio-educativo-revista-de-

Martínez, J. A. (2005). La lectura en la España contemporánea: Lectores, discursos y prácticas de lectura. Ayer, 58(2). 15-34. http://www.revistaayer.com/anteriores/42

Rocamora, N. (2015). Lasuper-estrategiadeStanislavski:Motivos deunmétodoparalainterpretación del autor contemporáneo (Tesis doctoral). Universidad de Grada, Granada. http://digibug. ugr.es/handle/10481/43554

Sánchez, L. E. (2012). La comprensión lectora en el currículo universitario. Diá-logos, 6(9), 21-36.

http://www.redicces.org.sv/jspui/bitstream/10972/2061/1/2.\%20La\%20 comprension\%20lectora.pdf

Solé, I. (2009). Motivación y lectura. Aula de Innovación Educativa, 179, 56-59. https://es.slideshare. net/bravomari35/motivacin-y-lectura-isabel-sol

Umaña Chaverri, J. O. (1989). La tregua: Censura y autocensura de una voz que escribe y se escribe. Letras, 20-21, 129-16. https://www.revistas.una.ac.cr/index.php/letras/article/ view/3653/3510

Valenzuela, L. (2014). Lección de arte (Colección El Elogio de la Educación. Consejo de mentes brillantes). Editorial del Magisterio "Benito Juaréz".

Villoro, J. (2014). La utilidad del deseo [Conferencia magistral]. En 34 Feria Internacional del Libro Infantil y Juvenil. Cenart. https://www.gob.mx/cultura/prensa/no-hay-modo-de-escribirsatisfactoriamente-para-ninos-sin-jugar-a-ser-filosofo-juan-villoro?state=published 